04

\title{
Генератор плазмы с магнитно-вихревой стабилизацией и возможности его применения
}

\author{
(C) Г.Н. Чурилов ${ }^{1,2}$, Н.С. Николаев ${ }^{1,2}$, К.В. Шичалин ${ }^{1}$, В.А. Лопатин ${ }^{2}$ \\ ${ }^{1}$ Сибирский федеральный университет, Красноярск, Россия \\ ${ }^{2}$ Институт физики им. Л.В. Киренского ФИЦ КНЦ СО РАН, Красноярск, Россия \\ E-mail: churilov@iph.krasn.ru
}

Поступило в Редакцию 21 сентября 2018 г.

\begin{abstract}
Описаны конструкция плазменного генератора, параметры получаемой плазмы и возможности ее применения для синтеза нанодисперсных порошков и оптической эмиссионной спектроскопии. В основе работы устройства лежит дуговой разряд переменного тока $(66 \mathrm{kHz})$ в струе аргона между охлаждаемыми водой металлическими электродами. Разряд стабилизируется изолирующим потоком газа (гелия, азота, воздуха), который подается тангенциально к оси разряда, и осевым магнитным полем. Плазма между электродами имеет форму цилиндра, удаленного от стенок камеры. Температура и электронная концентрация в сечении плазменного цилиндра изменяются вдоль радиуса и приобретают максимальное и минимальное значение.
\end{abstract}

DOI: 10.21883/PJTF.2019.01.47156.17533

В последнее время получила развитие сильноточная электроника переменного тока $\left(10^{4}-10^{6} \mathrm{~Hz}\right)$. Применение высокочастотных (ВЧ) токов позволило эффективно решить ряд задач: в области синтеза материалов, создания новых источников электромагнитного излучения и плазменных генераторов и т. д. [1-6]. В настоящей работе представлены результаты исследования разработанного нами плазменного генератора, частота тока питания которого составляет $66 \mathrm{kHz}$ и который обладает низкой эрозией электродов, высокой стабильностью разряда и образованного им плазменного потока. Для получения стабильного потока плазмы с целью возможного его использования для синтеза нанодисперсных порошков и оптического эмиссионного анализа нами был разработан, изготовлен и исследован в работе генератор плазмы (рис. 1). ВЧ-разряд 6 осуществлялся между двумя металлическими электродами. Верхний электрод 1 был выполнен в виде кольца из медной трубки и охлаждался водой. Нижний электрод 4, также охлаждаемый водой, выполнялся из медного стержня с осевым отверстием, через которое подавался аргон. Кольцо имело разрез и создавало магнитное поле в соответствии с текущим по нему током. Похожая конструкция была использована нами ранее [7].

Часть плазменного потока разряда подвергалась воздействию магнитного поля катушки 2, что приводило к стабилизации разряда и дополнительному ее подогреву. В качестве плазмообразующего газа использовался аргон, а в качестве стабилизирующего - азот или гелий. Плазмообразующий поток аргона подавался через осевое отверстие центрального электрода. Стабилизирующий поток 5 газа подавался тангенциально в плоскости, перпендикулярной потоку плазмообразующего газа, вблизи торца центрального электрода, что обеспечивало его вращение. Попадая в часть керамического сопла 3 меньшего диаметра, закрученный поток газа сжимается и увеличивает скорость своего вращения. Далее плазменный поток попадает в магнитное поле соленоида. Соленоид, включенный в первичную цепь последовательно с дуговым разрядом, создает в керамической части камеры с узким диаметром осевое магнитное поле. Пониженное давление, образующееся вследствие вращения газового потока, и осевое магнитное поле обеспечивают локализацию плазмы разряда вблизи оси, а также стабильность горения разряда. Благодаря этому на разряд постоянно действует сила Ампера, не позволяя току отклоняться от осевого направления и защищая стенку керамической камеры от перегрева и разрушения.

Измерение спектральных характеристик было выполнено на спектрографе PGS-2 с цифровой системой регистрации спектров ФЭК-9. Температура разряда измерялась методом относительных интенсивностей спектральных линий по атомарным линиям $\mathrm{CuI}-510.5$ и $521.8 \mathrm{~nm}$. Порошок меди вводился с потоком плазмообразующего газа (аргона), так как линий меди без его введения не наблюдалось. Причина этого явления рассмотрена далее. Электронная концентрация была рассчитана с помощью штарковского уширения линий водорода. Полученные значения хордовых интенсивностей были пересчитаны с помощью преобразования Абеля. Таким образом, были установлены истинные пространственные распределения как температуры, так и электронной концентрации. Были получены распределения температуры и электронной концентрации по радиусу плазменного столба для всего видимого потока плазмы (рис. 2, $a, b$ ). При диаметре выходного отверстия сопла $8 \mathrm{~mm}$ наблюдаемый диаметр плазменной струи составлял $4.2 \mathrm{~mm}$. Как видно из рисунка, в плазменном потоке существуют коаксиальные слои с различной температурой и электронной концентрацией. Условно по длине разряда можно выделить три области: I центральная „холодная“ область на расстоянии от оси 


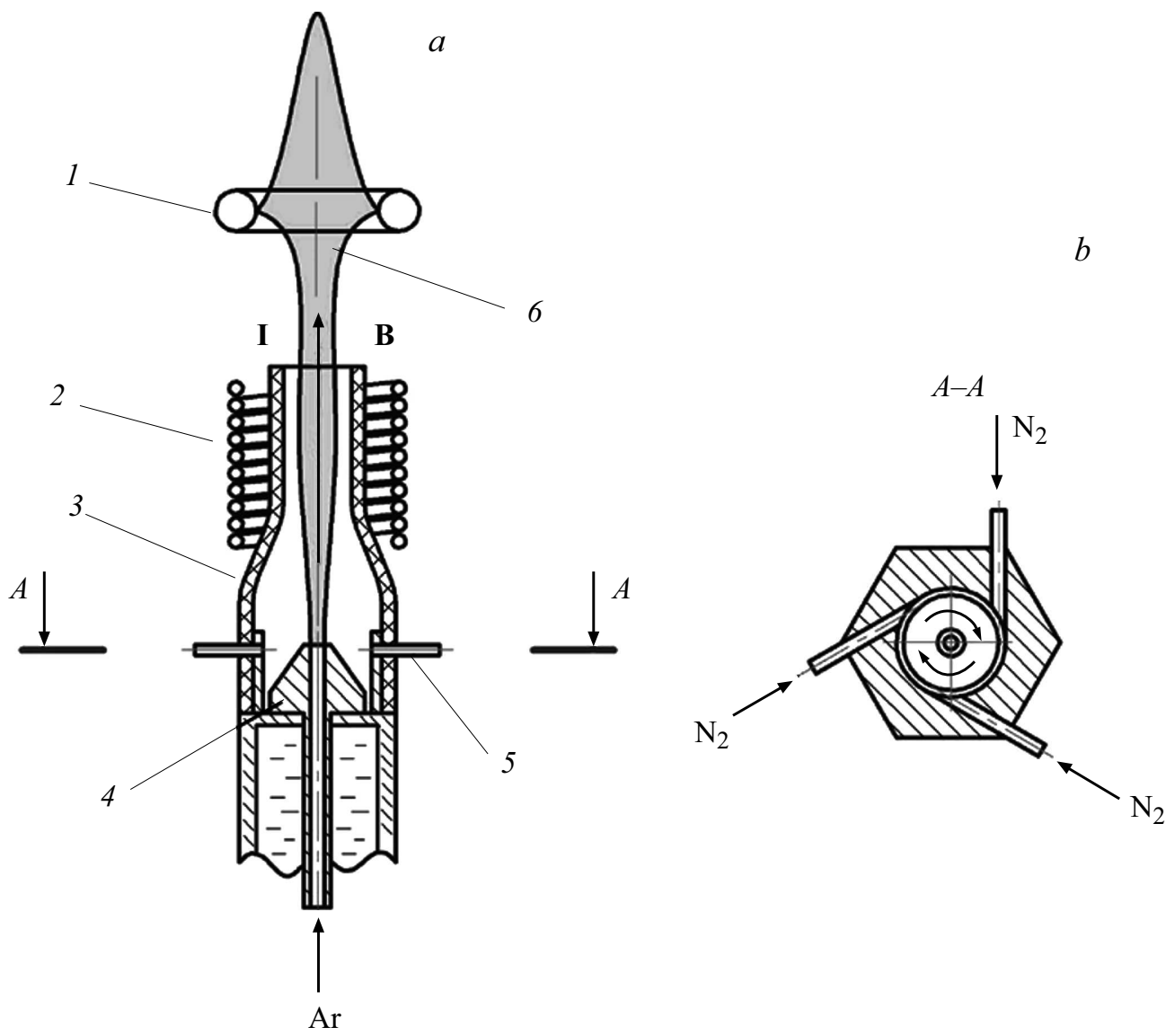

Рис. 1. Конструкция генератора плазмы с магнитно-вихревой стабилизацией разряда. $a$ - вертикальное сечение: вектор указывает направления тока и магнитной индукции в катушке (направления тока разряда и магнитного поля, создаваемого соленоидом, совпадают); $b$ - горизонтальное сечение со схемой подачи стабилизирующего газа.

0-0.7 mm; II - промежуточная „охлажденная“ область на расстоянии $0.8-1.5 \mathrm{~mm}$; III - крайняя „горячая“ область на расстоянии $1.6-2 \mathrm{~mm}$ (рис. $2, a)$. Наиболее ярко выражены эти области на сечениях, находящихся на расстоянии $2-3.5 \mathrm{~mm}$ от начала наблюдения разряда. Электронная концентрация на этих же сечениях ведет себя схожим образом, максимумы имеются в центре и на краю разряда. При этом на больших расстояниях осевой максимум электронной концентрации отсутствует, наблюдается плавный рост вблизи краевой области разряда. Для более „холодной“ области II эта тенденция нарушается.

Таким образом, стабилизация плазменного столба возникает за счет обоих процессов: градиента радиального давления и силы Ампера, действующей со стороны аксиального магнитного поля. Вращающийся горячий газ создает область пониженного давления, куда устремляются наиболее горячие слои плазмы. Аксиальное магнитное поле не позволяет току отклоняться от осевого движения вдоль канала сопла и касаться стенок сопла из-за силы Ампера.

Существенная разница в интенсивностях излучения внешнего слоя III и центрального слоя I указывает на различную внутреннюю энергию плазмы этих слоев.
В процессе горения дугового разряда в плазменном потоке возникает разделение плазмы на две составляющие с разными температурами и электронными концентрациями, а также с разной интенсивностью излучения. Экспериментальным путем было установлено, что аксиальное магнитное поле и вихревая подача стабилизирующего газа по отдельности не обеспечивали стабилизацию плазменного потока и неизменно приводили к разрушению сопла.

Кроме результатов исследования оптических эмиссионных спектров, приведенных выше, был установлен удивительный факт отсутствия излучения материала электродов (выполненных из меди) в случае, когда специально медь не вводилась (рис. 3).

Соотношение сигнал-фон определяется как отношение средней интенсивности излучения, определенной по трем линиям меди $(510.5,515.3$ и $521.8 \mathrm{~nm})$, к фону. Как видно из рис. $3, a$, максимум соотношения сигнал-фон $-760-$ приходится на расстояние $2 \mathrm{~mm}$ от нижнего торца электрода, если в плазме присутствует проба, подаваемая через осевое отверстие электрода. В том случае, когда проба отсутствовала, на высоте ниже $5 \mathrm{~mm}$ в спектре не наблюдалось линий материала электрода. Следовательно, материал электрода в 


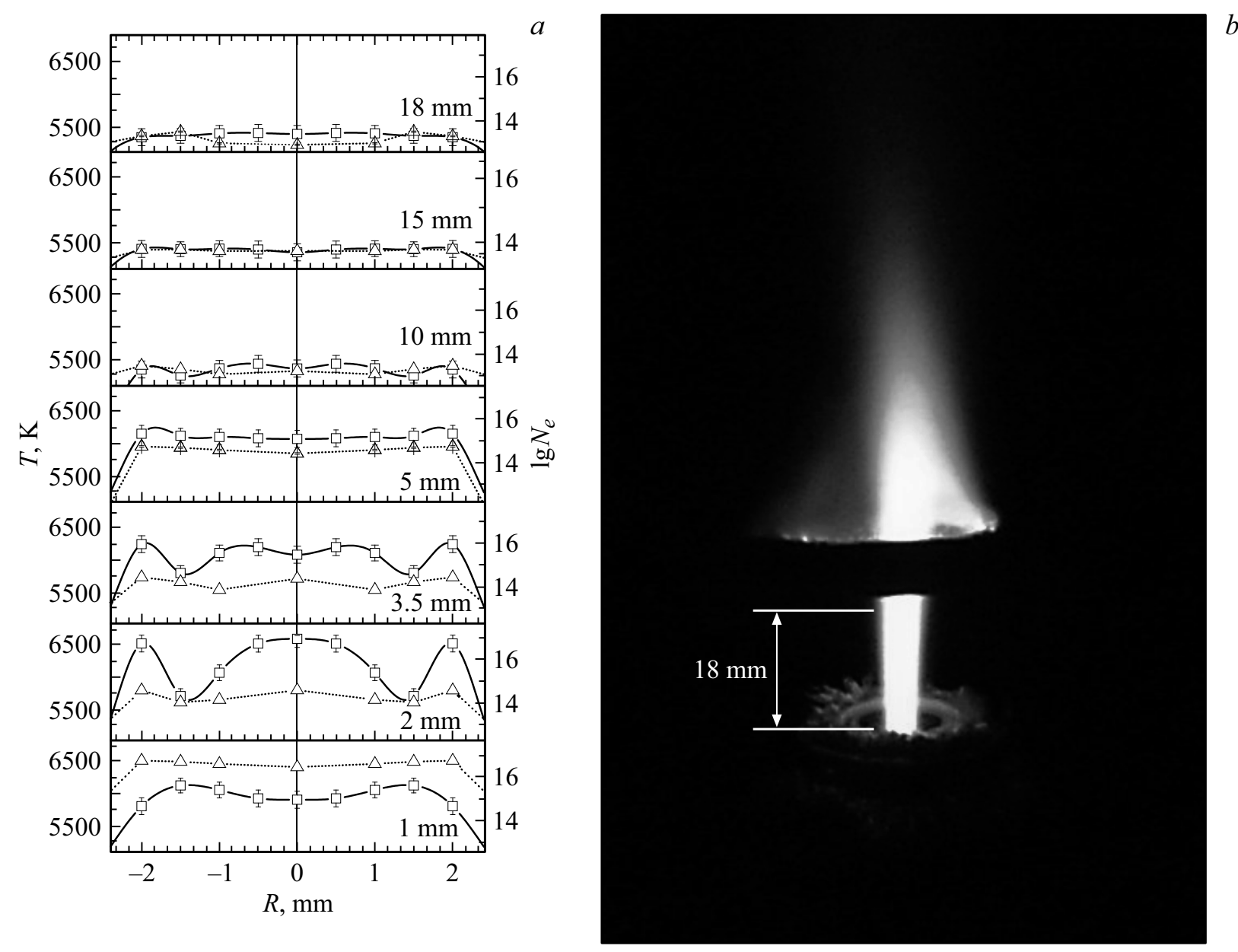

Рис. 2. $a$ - распределение температуры (сплошная линия) и электронной концентрации (пунктирная линия) по разрядному промежутку; $b-$ фотография разряда плазматрона с магнитно-вихревой стабилизацией, отмечена измеряемая часть разрядного промежутка.
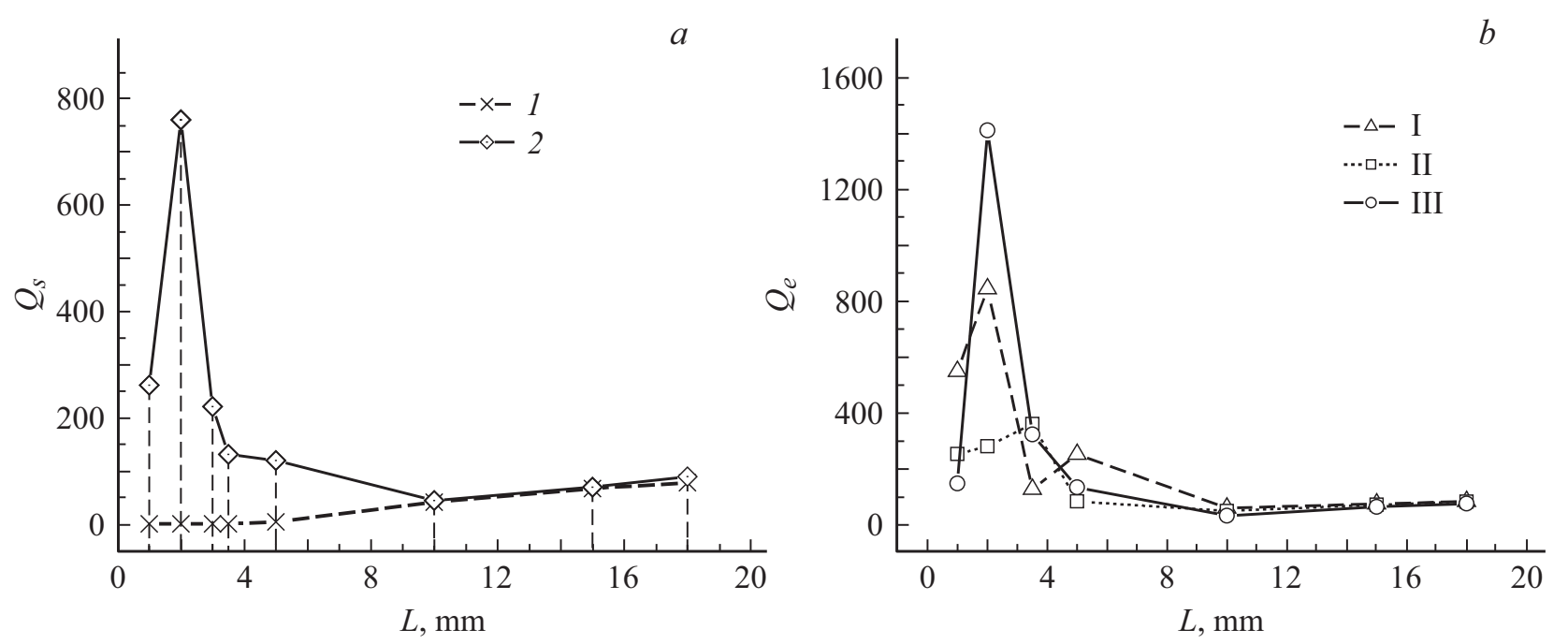

Рис. 3. Распределения соотношений сигнал-фон для разряда. $a) Q_{s}-$ средняя по хорде интенсивность излучения линий меди: 1 - без $\mathrm{Cu}, 2-$ с подачей $\mathrm{Cu}$ в разрядный промежуток; $b) Q_{e}-$ среднее значение в точке для различных температурных областей (I-III) разряда. Относительная погрешность измерений $2.0 \%$. 
данной области плазменной струи отсутствовал. Так же при подаче пробы в разрядный промежуток интенсивность излучения меняется для каждой из температурных областей. Максимальное значение соотношения сигнал-фон - 1410 - достигается на расстоянии $2 \mathrm{~mm}$ от выходного отверстия сопла в краевой области III.

Тот факт, что эрозия кольцевого электрода-индуктора составляет всего $10^{-12} \mathrm{~kg} / \mathrm{C}$, был установлен нами ранее и связан с воздействием сильного магнитного поля, приводящим к хаотическому движению электродных пятен по поверхности электрода [8]. Однако торцевой электрод всегда разрушался, хотя эрозия составляла уже $10^{-7}-10^{-8} \mathrm{~kg} / \mathrm{C}$. Исследования порошка, который был собран со стенок керамической камеры при работе плазменного генератора со стабилизирующим газом воздухом, позволили установить, что это нанодисперсные частицы оксида меди. Таким образом, центральный торцевой электрод распыляется, собирается в частицы и под действием центробежной силы наносится на внутреннюю поверхность цилиндрической камеры.

В заключение можно отметить, что дуговой ВЧ-плазмотрон с вихревой и магнитной стабилизацией отличается отсутствием линий материала электродов и высокими значениями соотношения сигнал-фон. Благодаря этому прибор может быть использован как перспективный источник света для оптической эмиссионной спектроскопии. Также показано, что его можно использовать для синтеза нанодисперсных порошков металлов, распыляя материал центрального электрода.

\section{Список литературы}

[1] Чурилов Г.Н. Источник света для спектрального анализа. Патент RU 2326353 C1. 10.06.2008. МПК G01J3/10.

[2] Chuvil'deev V.N., Blagoveshchenskiy Yu.V., Nokhrin A.V., Boldin M.S., Sakharov N.V., Isaeva N.V., Shotin S.V., Belkin O.A., Popov A.A., Smirnova E.S., Lantsev E.A. // J. Alloys Compd. 2017. V. 708. P. 547-561. https://doi.org/10.1016/j.jallcom.2017.03.035

[3] Krasovskii P.V., Samokhin A.V., Fadeev A.A., Alexeev N.V. // Adv. Powder Technol. 2016. V. 27. N 4. P. 1669-1676. https://doi.org/10.1016/j.apt.2016.05.031

[4] Карпов И.В., Ушаков А.В., Федоров Л.Ю., Лепешев А.А. // ЖТФ. 2014. Т. 84. В. 4. С. 93-97.

[5] Новиков И.Н., Кручинин А.М. // Письма в ЖТФ. 2014. Т. 40. B. 20. C. $76-81$.

[6] Зимин С.П., Амиров И.И., Наумов В.В., Гусева К.Е. // Письма в ЖТФ. 2018. Т. 44. В. 12. С. 32-38.

[7] Чурилов Г.Н., Лопатин В.А., Новиков П.В., Внукова Н.Г. // Приборы и техника эксперимента. 2001. № 4. С. 105-109.

[8] Внукова Н.Г. Установка для атомно-эмиссионного анализа и методика обработки спектров. Канд. дис. Красноярск, 2003. $98 \mathrm{c}$. 